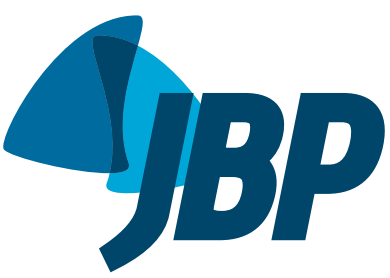

\title{
Diagnosing alpha-1 antitrypsin deficiency: does it prevent or improve the course of COPD?
}

\author{
Irma Godoy ${ }^{1}$
}

Alpha-1 antitrypsin (AAT) is a protein whose main function is the inhibition of neutrophil elastase. The gene that encodes AAT is transmitted by simple autosomal codominant Mendelian inheritance through two alleles, one from each parent. The normal allele is designated Pi*M, and the most common deficient alleles are the Pi*S and $\mathrm{Pi} * \mathrm{Z}$ alleles, which encode abnormal proteins that undergo polymerization in the liver. Therefore, $80-90 \%$ of the $Z$ proteins and $40-50 \%$ of the $S$ proteins are retained within the hepatocytes, grouped into polymers. The loss of the anti-inflammatory and antiproteolytic activity, together with the pro-inflammatory effects of polymers, contribute to protein degradation and the exacerbation of inflammation, resulting in an increased risk of developing COPD, with a predominance of emphysema, especially in smokers.

AAT deficiency (AATD) is a rare disease and, like most such diseases, is underdiagnosed. The diagnosis is usually made late (at an average patient age of 45 years), and estimates suggest that $85 \%$ of patients with AATD have gone un diagnosed. ${ }^{(1)}$ These findings indicate the low adherence to the recommendations of the World Health Organization, as well as to the guidelines of the American Thoracic Society and the European Respiratory Society, suggesting that patients with COPD or persistent airway obstruction should be tested for AATD. ${ }^{(2,3)}$ The potential reasons for misdiagnosis include a lack of knowledge about the disease, about the tests necessary for the diagnosis, the lack of availability of such tests, and about the algorithm required in order to confirm the diagnosis.

The prevalence of AATD varies depending on the population studied. Attempts to determine the prevalence of genetic predisposition in patient populations will inevitably overestimate the prevalence in the general population, whereas limiting screening to the healthy portion of the general population can underestimate the prevalence. In Europe, the prevalence of the $\mathrm{Pi}^{*} \mathrm{Z}$ mutation is highest in the northeastern region, where it ranges from 0.029 to $0.049 .{ }^{(4-6)}$ In the United States, the prevalence is similar $(0.019-0.030) .{ }^{(7,8)}$ In Asia, the prevalence is extremely low (0.006). ${ }^{(1)}$

The data presented in the study conducted by Russo et al., ${ }^{(9)}$ published in the current issue of the JBP, are unprecedented in that they show the prevalence of AATD in 926 COPD patients in five Brazilian states. The diagnosis of AATD was based on an AAT cut-off point of $<2.64 \mathrm{mg} / \mathrm{dL}$ in dried blood samples on filter paper. For patients in whom the AAT value was below the cut-off point, the serum concentration of AAT was determined. For those with a serum AAT concentration < $113 \mathrm{mg} /$ $\mathrm{dL}$, genetic sequencing was performed. In inconclusive cases, SERPINA gene sequencing was performed. Among the patients evaluated by Russo et al., ${ }^{\left({ }^{9}\right)}$ the AAT values indicated the need for additional investigation in $9.2 \%$, the serum AAT concentration was $<113 \mathrm{mg} / \mathrm{dL}$ in $2.6 \%$, and the prevalence of the PI*Z allele was $0.8 \%$, similar to that described in other countries. ${ }^{(9)}$

The study underscores the need to investigate AATD in patients with COPD, in accordance with the recommendations and guidelines mentioned above. ${ }^{(2,3)}$ The alternative strategy is to prioritize investigation for specific risk groups, including patients with early-onset emphysema or emphysema that is predominantly in the lower lobes, as well as family clusters of COPD patients or first-degree relatives of individuals diagnosed with moderate or severe AATD. ${ }^{(10)}$ It is also important to screen for AATD in individuals with unexplained liver disease, including newborns, children, and adults, as well as in adults with necrotizing panniculitis. Screening for AATD is recommended in adults with bronchiectasis of unclear etiology, adolescents with a persistent obstructive pattern, and adolescents with cytoplasmic-antineutrophil cytoplasmic antibody-positive vasculitis. ${ }^{(11)}$

Given that the main risk factor in individuals with AATD is smoking, which promotes the earlier emergence of COPD in smokers than in non-smokers, ${ }^{(12)}$ early identification of the disease allows preventive measures to be taken, the most important of which are avoiding smoking (active and passive) and exposure to environmental pollutants, both of which are determinants of the prognosis of COPD. Early identification of COPD allows lung function to be monitored and the therapeutic decision to administer supplemental therapy while pulmonary function is still relatively preserved. The treatment of patients with COPD and AATD includes the usual therapy for the disease (smoking cessation, vaccination, use of bronchodilators, rehabilitation, and long-term home oxygen therapy when indicated). ${ }^{(10)}$ The specific treatment of AAT replacement through the administration of concentrated purified AAT from human plasma is now available in Brazil.(11) However, that treatment is extremely expensive (approximately US\$100,000 per year); the indications for its use and its efficacy are not well defined; and it is not recommended by the US National Institute for Health and Care Excellence, ${ }^{(13)}$ although its use can be considered in young patients with COPD, according to the Global Initiative for Chronic Obstructive Lung Disease (grade C recommendation). ${ }^{(14,15)}$

In brief, despite the recommendations of the World Health Organization and the American Thoracic Society/ European Respiratory Society, many physicians and COPD patients do not fully comprehend the risk of a rapid increase in airway obstruction associated with AATD. 
With the availability of effective smoking cessation interventions, testing patients with COPD, especially those most at risk, to identify carriers of AATD is important and justifiable. During the treatment of COPD, efforts should be directed toward early detection of airway obstruction and avoiding exposure to risk factors, especially smoking, the most important intervention to reduce the progression of the disease.

\section{REFERENCES}

1. Greulich T, Vogelmeier CF. Alpha-1-antitrypsin deficiency: increasing awareness and improving diagnosis. Ther Adv Respir Dis 2016;10(1):72-84. http://dx.doi.org/10.1177/1753465815602162

2. Alpha 1-antitrypsin deficiency: memorandum from a WHO meeting Bull World Health Organ. 1997;75(5):397-415.

3. American Thoracic Society; European Respiratory. American Thoracic Society/European Respiratory Society statement: standards for the diagnosis and management of individuals with alpha- 1 antitrypsin deficiency. Am J Respir Crit Care Med. 2003;168(7):818-900. http:// dx.doi.org/10.1164/rccm.168.7.818

4. Dahl M, Tybjaerg-Hansen A, Lange P, Vestbo J, Nordestgaard BG. Change in lung function and morbidity from chronic obstructive pulmonary disease in alpha1-antitrypsin MZ heterozygotes: A longitudinal study of the general population. Ann Intern Med. 2002;136(4):270-9. http://dx.doi.org/10.7326/0003-4819-136-4 200202190-00006

5. Hutchison DC. Alpha 1-antitrypsin deficiency in Europe: geographica distribution of Pi types S and Z. Respir Med. 1998;92(3):367-77. http://dx.doi.org/10.1016/S0954-6111(98)90278-5

6. Sveger T. Liver disease in alpha1-antitrypsin deficiency detected by screening of 200,000 infants. N Engl J Med. 1976;294(24):1316-21. http://dx.doi.org/10.1056/NEJM197606102942404

7. Lieberman J, Winter B, Sastre A. Alpha 1-antitrypsin Pi-types in 965 COPD patients. Chest. 1986;89(3):370-3. http://dx.doi.org/10.1378/ chest.89.3.370

8. Morse JO, Lebowitz MD, Knudson RJ, Burrows B. Relation of protease inhibitor phenotypes to obstructive lung diseases in a community. N Engl J Med. 1977;296(21):1190-4. http://dx.doi.

\section{org/10.1056/NEJM197705262962102}

9. Russo R, Nascimento OA, Manzano B, Ivanaga IT, Fritscher L, Lundgren $\mathrm{F}$, et al. Prevalence of deficiency of alpha-1 antitrypsin and allele frequency in patients with COPD in Brazil. J Bras Pneumol. 2016;42(5):311-16.

10. Ferrarotti I, Poplawska-Wisniewska B, Trevisan MT, Koepke J, Drese M, Koczulla R, et al. How Can We Improve the Detection of Alpha1Antitrypsin Deficiency? PLoS One. 2015;10(8):e0135316. http:// dx.doi.org/10.1371/journal.pone.0135316

11. Stoller JK, Aboussouan LS. A review of ם1-antitrypsin deficiency. Am J Respir Crit Care Med. 2012;185(3):246-59. http://dx.doi org/10.1164/rccm.201108-1428Cl

12. Petrache I, Fijalkowska I, Zhen L, Medler TR, Brown E, Cruz $\mathrm{P}$, et al. A novel antiapoptotic role for alpha1-antitrypsin in the prevention of pulmonary emphysema. Am J Respir Crit Care Med. 2006;173(11):1222-8. $\quad$ http://dx.doi.org/10.1164/rccm.200512$18420 \mathrm{C}$

13. National Institute for Health and Care Excellence (NICE) [homepage on the Internet]. London: NICE; c2016 [updated 2010 Jun; cited 2016 Jul 18]. Chronic obstructive pulmonary disease in over 16s: diagnosis and management. NICE guidelines [CG101]. Available from: https:// www.nice.org.uk/guidance/cg101/chapter/1-guidance

14. Global Initiative for Chronic Obstructive Lung Disease (GOLD) [homepage on the Internet] Bethesda: GOLD [cited 2016 Jan 11]. Available from: http://goldcopd.org/

15. Stoller JK. Alpha-1 antitrypsin deficiency: An underrecognized, treatable cause of COPD. Cleve Clin J Med. 2016;83(7):507-14. 